\title{
More medical graduates than ever choosing family practice
}

$\mathrm{T}$ he College of Family Physicians of Canada has moved closer to its ultimate goal of having $45 \%$ of medical school graduates embrace its specialty, with $38.5 \%$ of graduates selecting family practice as their first choice of discipline in 2015.

That percentage is little changed from 2014's $38.2 \%$, but gets the college within a hair of its target of $40 \%$ by 2017 , and 45\% thereafter, says Dr. Pamela EisenerParsche, the college's executive director of academic family medicine.

"We're delighted to be at an all-time high," she said. "Our ultimate feeling is that if $45 \%$ of physicians choose family medicine, it would be an appropriate mix for the population. It's very achievable."

The Canadian Resident Matching Service (CaRMS), the not-for-profit organization that matches graduates to residency programs, released its analysis of this year's process at the conference. In highlighting the overall results, CaRMS CEO Sandra Banner noted that more men are now choosing family practice than in previous years, an upswing of about 5\% since 2013.

"There's also a decline in men choosing surgery, probably to do with a lot of the hospital challenges concerning resources for operating time," Banner said. "We don't want a field dominated entirely by one sex or the other. We need the diversity."

Internal medicine and surgical specialties were the first choice of $13.6 \%$ and $12.5 \%$ of graduates respectively this year, with just $6 \%$ choosing psychiatry, $5.5 \%$ pediatrics and $4.8 \%$ anesthesiology. Diagnostic radiology and dermatology were the least popular disciplines, the choice of just $3.4 \%$ and $1.8 \%$, respectively.

There were 5285 applicants to 909 residency programs, and $90 \%$ were matched to their first choice of discipline, although not necessarily to their desired program and university. Sixty percent of applicants were matched with one of their top three choices in a specific program and university.

"There is always a lot of anxiety around CaRMS because it's such a highstakes process," said Dr. Tom McLaughlin, a second-year resident in

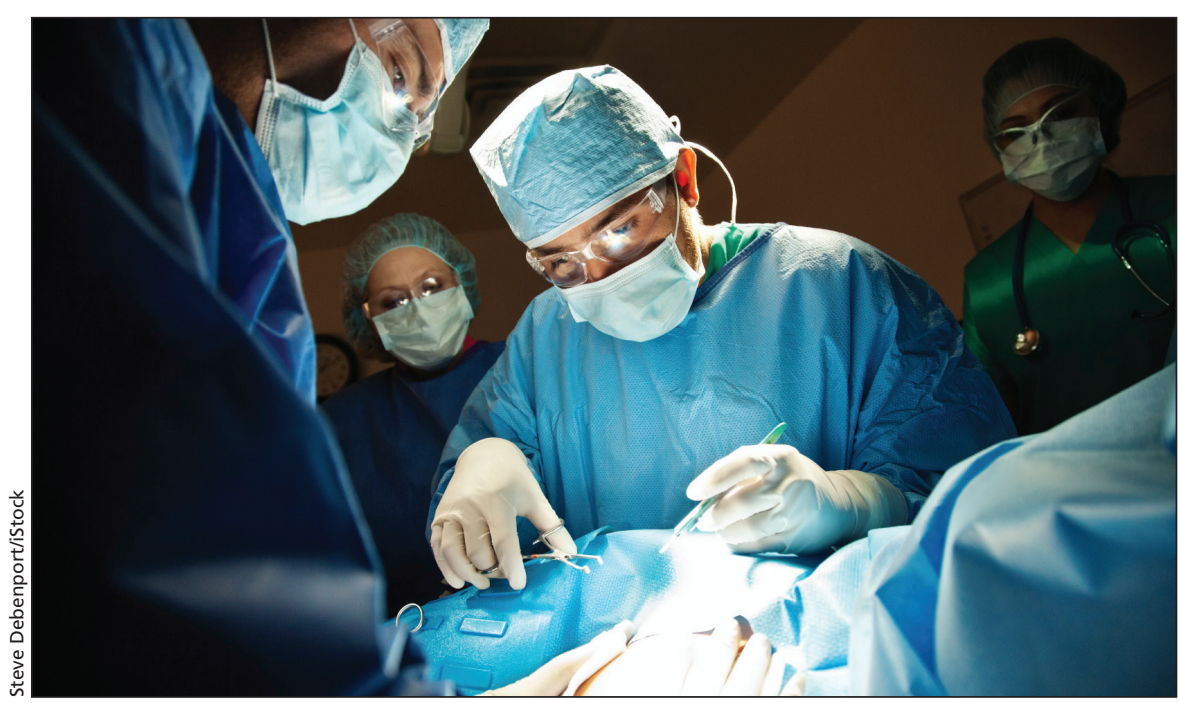

Fewer male medical graduates are choosing to become surgeons, possibly because of restrictions on operating time.

pediatrics at the University of Toronto and a spokesperson for Resident Doctors of Canada. "You only get one shot at the CaRMs match, whereas you might apply multiple times to medical school."

Family medicine as a first-choice specialty has been growng steadily since 2004 , when just $24 \%$ of graduates picked the specialty. The shift is occurring at the same time as other specialties, notably surgery, are reporting some unemployment.

"There is virtually no unemployment in family medicine," EisenerParsche pointed out. She credits the flexible nature of the discipline, as well as new remuneration models across the country that favour capitation instead of pure fee-for-service, as among the reasons for the discipline's popularity.

The decision by many universities to offer undergraduate medical education at other locations in addition to its main medical school - as the University of British Columbia does at its Prince George, Victoria and Kelowna campuses - may also have influenced the rise in family medicine as a favourite discipline, said Banner.

"They are studying in smaller communities, their undergraduate education is often delivered by family physicians ... so possibly that has an ... influence on students choosing the career."

With an estimated one in six Canadians lacking a family doctor, according to the Canadian Institute for Health Information, medical schools have scrambled to meet the need. The number of family medicine residency slots across the country has grown to 1512 in 2015 , up from 469 in 2001 - a $322 \%$ increase, Banner said. Almost all the available spots, 98\%, were filled this year after both matching iterations. Only 44 family residency positions remained unfilled at the end of the matching process.

In one major change to recent trends in the matching process, $21 \%$ fewer international medical graduates applied to residency programs at Canadian medical schools this year compared to 2014. Banner believes the decline may be attributable to the requirement in all provinces except Saskatchewan that international graduates, including Canadians who study abroad, must now write the National Assessment Collaboration examination before applying, at a cost of more than $\$ 2100$.

"Perhaps not all of our international medical graduates were ready to take that exam when it became mandatory. That may be different next year."

Of the 421 international medical graduates matched this year, $50 \%$ will train in Ontario, $13 \%$ in British Columbia, $12 \%$ in Quebec and 10\% in Alberta, with the rest in the remaining provinces. — Laura Eggertson, Ottawa, Ont.

CMAJ 2015. DOI:10.1503/cmaj.109-5054 